\section{APLICACIÓN DE LA IMAGEN MULTIESPECTRAL AL ESTUDIO Y CONSERVACIÓN DEL ARTE RUPESTRE POSTPALEOLÍTICO}

\author{
THE USE OF MULTIBAND IMAGING \\ FOR THE STUDY AND PRESERVATION \\ OF POST-PALEOLITHIC ROCK ART
}

\author{
JUAN MANUEL VICENT GARCÍA (*) \\ IGNACIO MONTERO RUÍZ (*) \\ ÁNGEL L. RODRÍGUEZ ALCALDE (**) \\ M. ${ }^{a}$ ISABEL MARTÍNEZ NAVARRETE (*) \\ TERESA CHAPA BRUNET (**)
}

\section{RESUMEN}

El deterioro que padece el arte rupestre tanto por factores ambientales como antrópicos atañe a su conservación e investigación en el futuro. La docụmentación gráfica, en algunos casos el único vestigio disponible, se ve limitada también por problemas de conservación a largo plazo, en especial cuando se trata de fotografía en color. En este trabajo se plantean nuevas líneas de investigación para solventar estos problemas a partir de una investigación en curso en el Departamento de Prehistoria del Centro de Estudios Históricos (CSIC). Se trata de la conversión del importante archivo fotográfico del Corpus de Pintura Rupestre Levantina a formatos digitales (Kodak Photo CD) y la aplicación del tratamiento digital de imagen multiespectral a la investigación de estas manifestaciones artísticas.

(*) Departamento de Prehistoria. Centro de Estudios Históricos (CSIC). Serrano, 13. 28001 Madrid. Email chvg1b@fresno.csic.es.

(**) Departamento de Prehistoria. Facultad de Geografía e Historia. Universidad Complutense de Madrid. Ciudad Universitaria, s/n. 28040 Madrid. Email tchapa@eucmax.sim.ucm.es.

El artículo fue remitido en su versión final el 14-XI-96.

\begin{abstract}
Rock art deteriorates because of both environmental factors and visitor erosion which affect its conservation and, therefore, its study. Graphic recording carried out in the past is sometimes the only recorded evidence for what once existed. However, the graphic record also presents problems of preservation on the long-term, a problem particularly highlighted on modern color photographic materials. In this paper we deal with new approaches to solve this problem. We illustrate our work with the photographic collection about Levantine rock art, which belongs to the CSIC, and is held in the Department of Prehistory of Centro de Estudios Historicos. Two methods are highlighted: the use of the new Kodak Photo CD system, and the multiband Digital Imaging analysis.
\end{abstract}

Palabras clave: Arte Rupestre Levantino. Imagen multiespectral. Kodak Photo CD. Conservación. Informática. Península Ibérica

Key words: Levantine Rock Art. Multiband imaging. Kodak Photo CD. Conservation. Computers. Iberian Peninsula 


\section{INTRODUCCIÓN}

Presentamos en este trabajo un avance del proyecto de investigación "Aplicaciones del proceso digital de imagen al estudio y conservación del arte repestre prehistórico" (DGICYT PB-95-0227). El planteamiento de este programa es el resultado de la convergencia de dos líneas de investigación que en la actualidad se desarrollan en el Departamento de Prehistoria del Centro de Estudios Históricos (C.S.I.C.) (Vicent, 1993).

La primera de ellas es la aplicación de las técnicas de procesamiento digital de la imagen a la conservación y potenciación del conjunto de colecciones fotográficas sobre arte prehistórico que constituyen el Archivo de Arte Rupestre (AAR) del Departamento. Los trabajos en este sentido se iniciaron en 1991 concentrándose en la más valiosa de estas colecciones desde el punto de vista documental: el Corpus de Pintura Ruprestre Levantina (CPRL) (1).

La segunda línea de investigación es el desarrollo de las aplicaciones arqueológicas de la Teledetección Espacial, particularmente en el campo de la Arqueología del Paisaje. Como se verá la propuesta que presentamos consiste sencillamente en el ensayo de una transposición controlada de algunos de los enfoques y técnicas de este último campo a un contexto de aplicación diferente. El propósito del proyecto es evaluar experimentalmente la viabilidad de esta transposición y establecer las condiciones de su aplicación óptima.

Este proceso de convergencia ha sido posible gracias a la creación del Laboratorio de proceso digital de imagen y teledetección del Departamento de Prehistoria, que desde 1995 proporciona el apoyo técnico tanto a los trabajos de digitalización del AAR como a los diver-

(1) Proyecto de la DGYCIT (PB92-088) titulado "Bases para la investigación del arte rupestre postpaleolítico en la $\mathrm{Pe}$ nínsula Ibérica: el archivo de arte rupestre del Departamento de Prehistoria del C.E.H. del C.S.I.C.", dirigido por Juan Manuel Vicent García y con la participación de Teresa Chapa Brunet, Almudena Hernando Gonzalo y M. ${ }^{a}$ Isabel Martínez Navarrete.

T. P., 53, n. $^{\circ} 2,1996$ sos proyectos de Arqueología del Paisaje emprendidos por sus miembros.

Ese campo es todavía experimental, pero tiene amplias posibilidades de desarrollo en el estudio y conservación de obras de arte. En general han venido utilizándose distintas técnicas de obtención de imágenes con un carácter documental que han permitido mejorar la percepción visual de las mismas o descubrir aspectos ocultos a la visión humana. De hecho la aplicación de imágenes ultravioleta, infrarrojas, la reflectografía o la radiografía se ha manifestado como una opción viable de investigación. Ahora se pretende avanzar un paso más y explorar todas las potencialidades que algunos de esos tipos de imágenes poseen mediante la aplicación de técnicas de trabajo desarrolladas hasta la fecha en la teledetección espacial.

'La utilización del tratamiento digital de imágenes de arte rupestre postpaleolítico obtenidas en diversas longitudes de onda de la misma manera que en teledetección espacial puede permitir identificar, caracterizar y descubrir aspectos desconocidos hasta el momento de las técnicas pictóricas, la organización compositiva y la ejecución de los paneles, así como revelar problemas de conservación y deterioro de las pinturas. Posibilita además un seguimiento temporal de su estado y, por tanto, constituye una herramienta para el diagnóstico y la aplicación de estrategias para la conservación de las mismas.

La posibilidad de aplicación de estas ideas generales es el principio de la respuesta diferencial de la materia a la energía en las distintas longitudes de onda de la radiación electromagnética. En nuestro caso, se trata de desarrollar una estrategia de trabajo que determine la opción óptima y de mayor rendimiento informativo entre las distintas posibilidades de captura de una imagen en longitudes de onda diferentes (tipos de sensores, resolución espectral y espacial, etc.), y que permita diferenciar los cuatro elementos básicos que aparecen en las imágenes de Arte Levantino (roca base o soporte, pigmentos orgánicos e inorgánicos, humedad del medio y microorganismos presentes) atendiendo a los problemas específicos que cada uno de ellos plantea. 


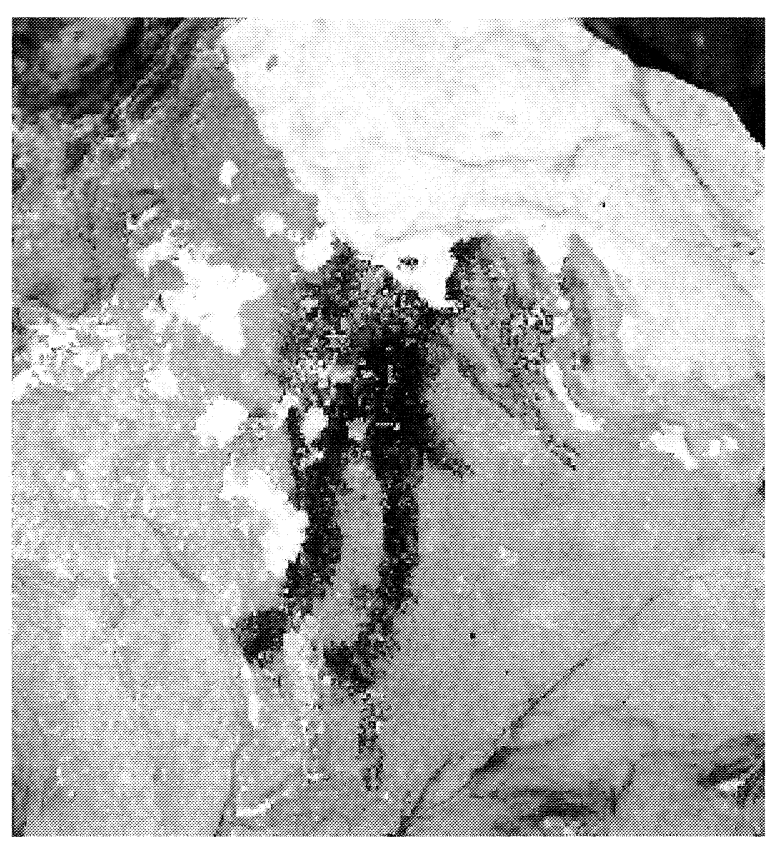

Lám. I. Figura humana deteriorada (figura 9c del abril III de Cueva Remigia, Barranco de la Gasulla, Ares del Maestre, Castellón). Tamaño 5,5 cm. Fotografía tomada el 18-6-71 (CPRL del Departamento de Prehistoria del C.E.H.).

\section{PROBLEMAS DE LA PINTURA RUPESTRE POSTPALEOLÍTICA EN LA PENÍNSULA IBÉRICA}

El arte rupestre postpaleolítico presenta en la actualidad un conjunto de limitaciones que inciden de forma negativa en su estudio. Los esfuerzos dedicados a su interpretación y significado, así como a la documentación de nuevos conjuntos no se ven acompañados por estrategias destinadas a salvaguardar este patrimonio y a profundizar en aspectos globales de la investigación. Además, en el caso de las manifestaciones artísticas pintadas, sus circunstancias concretas de ubicación y ejecución actúan de manera negativa para su conservación y limitan notablemente las posibilidades de estudio futuro.

Las agresiones que las pinturas han de soportar son diversos tipos de actos vandálicos (desde los modernos grafittis hasta el robo de los paneles arrancando las piedras) y factores ambientales desfavorables (Beltrán, 1982: 16-17). Las actuales lluvias ácidas, filtraciones, grietas, descascarillados, y cambios bruscos de temperatura a los que se ven sometidas por su ubicación en espacios abiertos, y en muchos casos poco protegidos, impiden crear condiciones de estabilidad como las que suelen existir en los espacios donde se localizan la mayor parte de las manifestaciones artísticas paleolíticas (interior de cuevas).

Consecuencia de todo ello ha sido la destrucción parcial (Lám. I) o completa de numerosos conjuntos o figuras que, en el mejor de los casos, han quedado documentados a través de calcos o imágenes fotográficas. Estos soportes gráficos, sin embargo, no representan una garantía documental permanente y corren el riesgo de desaparición debido a la fragilidad y/o alteración de los mismos. Este problema se ha puesto recientemente de manifiesto y exige la toma de una serie de acciones para afrontarlo.

El trabajo de digitalización del CPRL es una de ellas. Desde 1991 se vienen promoviendo en el Departamento de Prehistoria del C.E.H. diversas iniciativas destinadas a asegurar la conservación de este archivo, mejorar sus condiciones de acceso para los investigadores y potenciar su importancia científica en el contexto de los estudios de arte prehistórico. El Corpus contiene documentación completa sobre 99 estaciones rupestres, agrupadas en 54 conjuntos, pertenecientes a las comunidades autónomas de Aragón, CastillaLa Mancha, Cataluña, Murcia y Valencia y fue realizado entre los años 1971 y 1976 por el fotógrafo valenciano Fernando Gil Carlés (de ahí que se le conozca genéricamente como "Archivo Gil Carlés") con la colaboración de diversos arqueólogos bajo la dirección del profesor Almagro Basch (Vicent García, 1993 y 1994).

En esta tarea de conservación se ha optado por el uso de nuevas tecnologías informáticas en vez de recurrir al duplicado de originales, único procedimiento asequible y disponible hasta hace unos pocos años (2). Su principal limitación reside en que, al emplearse el mismo tipo de soporte físico, y aunque desde un principio puedan mejorarse las condiciones de almacenamiento y elegirse películas con mayor estabilidad, los problemas de conservación únicamente se postponen. Por el contrario el pro-

(2) El duplicado ha sido el sistema seguido para preservar los archivos fotográficos en algunas instituciones (Fletcher, 1992; Lautenbach, 1992; Koch y Grubet, 1994). 
ceso de digitalización presenta numerosas ventajas en estas facetas de conservación y almacenamiento y se beneficia de las opciones de trabajo y reproducción que posee la información conservada en ficheros informáticos, tanto por su facilidad de acceso, rapidez en la consulta selectiva, como por evitar la manipulación directa de originales.

Sin embargo, las potencialidades que la digitalización de imágenes tiene en la actualidad son mucho mayores que el simple almacenamiento y reproducibilidad del material y abren nuevas vías para desarrollar una investigación histórica y artística. La incorporación de la imagen a una base de datos documental constituye una herramienta indispensable para la investigación, pero ha de ir acompañada de otras estrategias que complementen la información disponible y el acceso a la misma.

\section{APLICACIÓN DE NUEVAS TECNOLOGÍAS EN OBRAS DE ARTE: ANTECEDENTES}

Las principales aplicaciones de métodos científicos al estudio de obras de arte en general y al arte rupestre en particular son (Lahanier, 1991): 1. examen de los objetos a través de diferentes tipos de imágenes; 2 . métodos analíticos para determinar su naturaleza; y 3. técnicas de datación.

De ellos nos interesa especialmente el primero, del que nos ocuparemos más adelante. En el campo de métodos analíticos destaca el trabajo realizado en los últimos años en los Laboratorios de Investigación de los Museos de Francia (por ejemplo Menu y Walter, 1992; Minzoni-Deroche et alii, 1995) para identificar pigmentos y aglutinantes en las pinturas rupestres, especialmente las de época paleolítica. En cuanto a la datación, el desarrollo de la técnica de carbono 14 mediante AMS, que trabaja con una cantidad mínima de muestra, ha permitido su aplicación directa con éxito a las pinturas rupestres en esta última década (Bednarik, 1993; Russ, 1994), suministrando en ciertos casos resultados sorprendentes en relación con algunas atribuciones estilísticas.
El registro de imágenes a partir de fotografía en blanco y negro se inicia casi desde los primeros momentos de la investigación de las manifestaciones artísticas prehistóricas (Moneva, 1993: 431-434). Sin embargo la calidad y las condiciones del registro no eran garantías suficientes para sustentar su estudio únicamente en esta herramienta. La distorsión que producían en la imagen las superficies irregulares u ocultamientos parciales bajo costras, además del escaso contraste obtenido en muchas ocasiones, obligaban a los investigadores a calcar las figuras representadas. La validez y fiabilidad de estos calcos, sin embargo, es un aspecto repetidamente criticado. Cuando se reestudian los abrigos y cavidades se rectifican los trabajos previos dado el componente subjetivo que interviene en su elaboración al haberse tomado decisiones en condiciones de percepción dificultosa.

La llegada de la fotografía en color supuso una mejora notable en la calidad de las imágenes, ya que el ojo humano tiene mayor capacidad de reconocimiento de matices en la gama de colores que en la de grises (Scanvic, 1989: 44). Sin embargo, para aceptar su validez había que superar los mismos problemas de registro que en la fotografía en blanco y negro, a los que se añadían otros nuevos como la distorsión del color que el procesado químico genera en la obtención de copias, su transformación y viraje con el tiempo y finalmente su deterioro, aspectos que influyen en la conservación de los archivos fotográficos.

La aplicación de otros tipos de imagen, en longitudes de onda diferentes a las del espectro visible (Fig. 1), amplió el grado de observación del ojo humano mostrando aspectos ocultos de la realidad, intrínsecos a la propia materia. Esta ampliación del registro, suministrado principalmente por las imágenes en infrarrojo (IR), no ha tenido una aplicación sistemática en el arte rupestre a pesar de algunos intentos tempranos como el de Pedersen (1954), aunque sí ha sido frecuente en el campo de la pintura sobre lienzo. Además del espectro infrarrojo obtenido por diversas técnicas más o menos complejas y costosas según la longitud de onda de trabajo deseada (fotografía, reflectografía o termografía), en general, en el estudio de las obras de

T. P., 53, n. ${ }^{\circ} 2,1996$ 


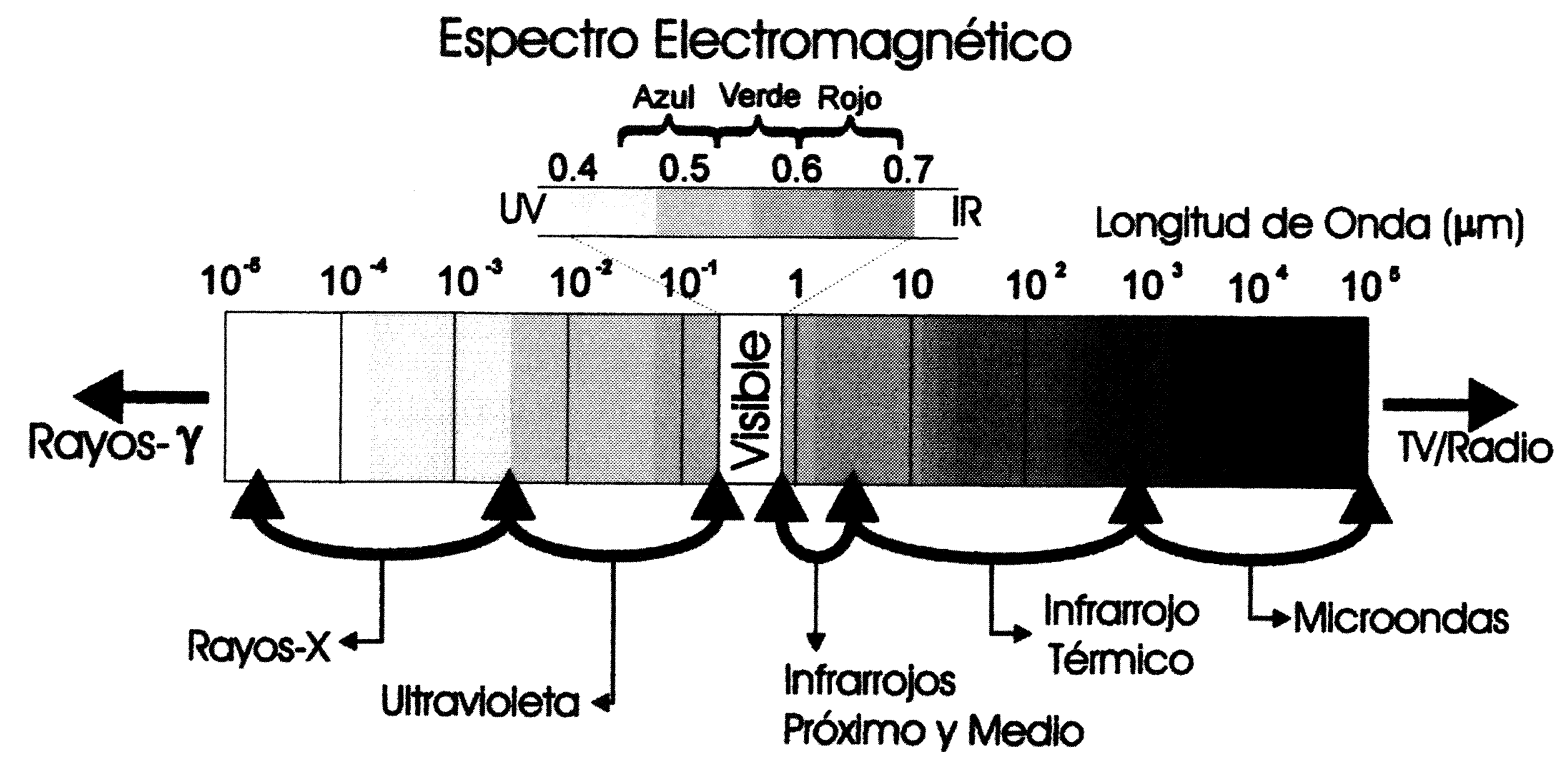

Fig. 1. Divisiones del espectro electromagnético.

arte se ha empleado también la fotografía ultravioleta y la radiografía.

Todos estos tipos de imágenes han tenido hasta la fecha una utilidad directa como medio de desvelar elementos no percibidos y se han usado mediante una comparación directa con el propio objeto o con la imagen visible del mismo, observando e interpretando las diferencias existentes. Es decir, su aplicación no ha buscado profundizar más allá de la comparación directa entre dos imágenes o lo que es lo mismo no ha trascendido el análisis visual.

La investigación aplicada ha buscado determinar las longitudes de onda más adecuadas o efectivas para cada caso de estudio ya sea de forma teórica (Delaney et alii, 1993) o a través de experiencias directas en campos tan diversos como los papiros (Andorlini et alii, 1993), tejidos (Andrew y Eastop, 1994) o pigmentos inorgánicos de pintura (Bacci et alii, 1992).

La introducción de la informática ha generado, también en este terreno, nuevas estrategias de trabajo para aprovechar al máximo la información contenida en las imágenes analógicas fotográficas, radiográficas o digitales generadas por alguna de las diversas técnicas referidas. De hecho el tratamiento digital de las imágenes, además de por las posibilidades que tiene en los procesos de restauración de fotografías, ha sido incorporado en los últimos años, principal y casi exclusivamente, a la mejora de la calidad de esas imágenes con el fin de destacar, resaltar o aislar los elementos presentes mediante la manipulación de las variables de contraste, intensidad, tono y saturación del color, o mediante la aplicación de filtros (por ejemplo Slack, 1994).

La mejora de imágenes para su análisis visual es ahora ampliamente usada en muy diversos campos gracias a la creciente accesibilidad del software comercial, acompañada por el aumento de las prestaciones del Hardware y sus periféricos, con costes asumibles por numerosas instituciones de investigación y empresas privadas. Pero este es un proceso todavía reciente, como se percibe en los primeros trabajos en esta línea aplicados directamente al arte rupestre (Ripp, 1983 y 1989) y no olvidemos que el sistema Kodak Photo CD no se comercializa en España hasta 1992. Así, por ejemplo, resultan ilustrativos los comentarios de Consens (1989) a las citadas propuestas de trabajo basadas en la digitalización de imágenes, donde manifestaba su escepticismo sobre la posibilidad de una aplicación generalizada de estas técnicas a la investigación del arte rupestre en 
un futuro próximo, ya que se escaparía a los presupuestos de investigación "normales".

Aunque afortunadamente las dudas de Consens no se han materializado, el tratamiento digital de imágenes no ha desarrollado aún todas sus potencialidades. De hecho en sus comentarios a Ripp (1989), Dickman (1989) avanzaba aún más en las propuestas y señalaba la potencialidad de la aplicación de las técnicas de trabajo de la teledetección espacial al arte rupestre. Desgraciadamente en este no se han cumplido las expectativas de Dickman, ya que no nos consta que algún equipo de investigación haya intentado desarrollar esta línea de trabajo. En la bibliografía especializada sólo hemos encontrado el precedente del trabajo de Aujoulat (1987) sobre arte parietal paleolítico, en el que se plantean muchas de las cuestiones que inciden en el tratamiento de imágenes multiespectrales. De manera paralela se han realizado trabajos experimentales sobre la utilización conjunta de imágenes en diferentes longitudes de onda para reconocer pigmentos en la pintura sobre tabla (Casini et alii, 1992) o la aplicación del análisis de componentes principales a un conjunto secuencial de imágenes (Baronti et alii, 1996).

\section{PRINCIPIOS DE LA TELEDETECCIÓN ESPACIAL APLICABLES A LAS IMÁGENES DE PINTURA RUPESTRE}

La tarea fundamental de un sistema de teledetección es caracterizar los elementos que forman parte de la superficie terrestre y para ello utiliza la interacción que se produce entre una fuente de energía (el sol) y la materia (la tierra). Esa interacción se basa en el Principio de Conservación de la Energía y en que la energía se manifiesta en diferentes longitudes de onda. Cuando ésta se encuentra ante una materia sólida es reflejada, absorbida o transmitida. La proporción de cada una de ellas está en función de las propiedades de la materia y de la naturaleza de las ondas electromagnéticas que constituyen la energía inicialmente aplicada. De este modo dos objetos de naturaleza diferente reflejan y absorben la energía en una misma longitud de onda en proporción diferente. Pero además hay que tener presente que la respuesta de los objetos varía según sus propiedades químicas o físicas, su configuración superficial y rugosidad, y según la intensidad de la iluminación y su ángulo de incidencia. Todos estos factores deben tenerse en cuenta para una correcta interpretación de los resultados y sobre éllos volveremos más adelante.

La reflectancia puede definirse como la relación entre la cantidad de radiaciones reflejadas por un material y la cantidad de energía recibida para una longitud de onda dada. Según la región del espectro electromagnético considerada, la reflectancia de un mismo material es variable (Scanvic, 1989: 27-28).

Estas variaciones son las responsables del color de los objetos dentro del espectro de la luz visible, y las que sustentan la posibilidad de reconocimiento de los distintos elementos integrantes de una imagen.

De manera simplificada, la teledetección espacial parte de la adquisición de imágenes en distintas longitudes de onda proporcionadas por unos sensores dispuestos en satélites. Estas imágenes son distribuidas en formatos digitales con unas determinadas características de resolución espacial, espectral y radiométrica. La imagen digital contiene la información en forma de una matriz bidimensional de elementos contiguos denominados celdillas (pixeles) expresadas en valores numéricos (formato numérico matricial).

Las imágenes por tanto pueden ser tratadas mediante procedimientos matemáticos a partir del principio de la existencia de diferencias de reflectancia entre bandas espectrales de un mismo material. Esas diferencias caracterizan al material y constituyen lo que se llama signatura espectral. La reflectancia de los materiales ha sido estudiada en laboratorio en las partes visibles y del IR próximo, siendo indispensable conocer la signatura espectral de los diferentes elementos para la comprensión y funcionamiento de este método.

Además ciertos factores pueden distorsionar la identificación de los distintos elementos para un fin determinado. Además del aire y la nubosidad o humedad ambiental que deben ser atravesados por la energía en el caso de la teledetección espacial, influyen la intensidad de iluminación, el ángulo de incidencia de la misma

T. P., 53, n. ${ }^{\circ} 2,1996$ 
que genera sombras o el propio tipo de cobertura del suelo que, en los casos de finalidades de identificación geológica, enmascara las cualidades que deben ser investigadas por lo que es necesario recurrir a combinaciones de imágenes alternativas que ayuden a diferenciar elementos.

A partir del trabajo de corrección se siguen diversas estrategias entre las que se incluye el realce de las imágenes y las transformaciones globales, definidas como las operaciones destinadas a la creación de nuevas imágenes a partir de la combinación lineal de bandas de la imagen original con el fin de hacer evidentes determinados rasgos o aislar algún tipo de información de interés (Pinilla, 1995: 187).

\section{ESTRATEGIAS PARA LA ADQUISICIÓN DE IMÁGENES MULTIESPECTRALES}

La aplicación a otros campos de las técnicas de trabajo con imágenes multiespectrales desarrolladas por los laboratorios de teledetección debe plantearse mediante unos objetivos claros sobre la información que se quiere obtener y a partir de que recursos es posible obtenerla. Quedan por resolver, sin embargo, las estrategias de adquisición de las imágenes y de experimentación para diseñar las combinaciones de trabajo adecuadas en función de los elementos presentes en cada caso concreto. La respuesta espectral de los materiales es conocida parcialmente por la experiencia previa que proporciona la teledetección. Pero en su aplicación a la pintura rupestre postpaleolítica hay que tener en cuenta que las condiciones en las que se van a registrar las imágenes son diferentes a las que se obtienen por un satélite. Finalmente el procesado y clasificación de la imagen nos permitirá llegar a unos resultados que deberán ser evaluados.

Por tanto el esquema de trabajo que ha de seguirse con las imágenes debe atender a los siguientes aspectos:

1. Fase de adquisición

2. Fase de procesado

3. Fase de análisis

3a. Estudio visual y matemático de la variabilidad interna de la imagen

3b. Clasificación de la imagen y asignación

3c. Toma de decisiones
Para la realización de las mismas es necesario partir de una evaluación preliminar de los elementos integrantes de la imagen que en el caso de la asignación ( $3 \mathrm{c}$ ) debe acompañarse de una identificación directa de los diferentes materiales a través del correspondiente análisis.

\section{A. Componentes de la pintura rupestre postpaleolítica}

En la pintura rupestre hay que discriminar el pigmento, compuesto por elementos orgánicos e inorgánicos, del soporte que, en la mayor parte de los casos, son rocas de naturaleza calcárea (calizas).

En los pigmentos es necesario identificar sus compuestos minerales constituyentes ya que, aunque parece que nunca se combinan colores en una misma figura, dentro de la pintura esquemática y del arte levantino existe variedad de tonos, especialmente en los rojos y ocres, y en menor proporción los negros y blancos (Beltrán, 1982: 20; Acosta, 1986: 268 y 280).

Tradicionalmente se ha considerado el empleo de hematites, otros óxidos de hierro y óxidos de manganeso en la elaboración de las pinturas prehistóricas. Estos compuestos han sido identificados analíticamente en algunas cuevas paleolíticas y postpaleolíticas francesas (Menu y Walter, 1992; Hameu et alii, 1995) y en algunos abrigos de la Comarca de Santolea en la provincia de Teruel (Beltran, 1982: 22). Además de estos minerales, en ciertas pinturas se ha detectado la presencia de compuestos orgánicos, ya sea como pigmentos, como es el caso del carbón, o como aglutinantes. Entre estos últimos pueden citarse proteínas animales procedentes de tejidos grasos o sangre o la utilización de fibras vegetales (Bednarik, 1993: 49).

La aplicación experimental de las técnicas de tratamiento digital a las imágenes del arte esquemático y levantino de la Península Ibérica exige conocer con exactitud la naturaleza de los pigmentos empleados y determinar sus signaturas espectrales. Por ello dentro de la propuesta inicial de trabajo se contempla el estudio analítico de muestras procedentes de las pinturas seleccionadas para las pruebas experimentales, así como la utilización de radiómetros de campo. 


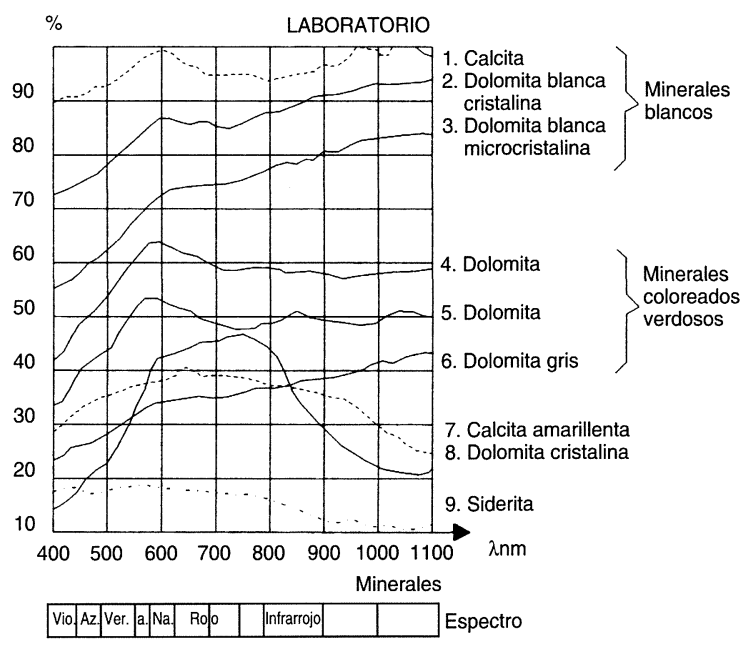

Fig. 2. Reflectancia de rocas obtenida experimentalmente en laboratorio (según Scanvic, 1989: Fig. 23).

La identificación genérica de los soportes es más sencilla ya que el problema de la limitación en la toma de muestras no existe, aunque un estudio completo requiere el empleo de varias técnicas analíticas. La ubicación mayoritaria de estas pinturas es en abrigos u oquedades de naturaleza caliza formadas por procesos erosivos naturales, aunque también aparecen en otros soportes como areniscas (Benito et alii, 199192). El comportamiento espectral de este tipo de rocas y de muchas otras es sobradamente conocido (Vrhel et alii, 1994). A pesar de la variación de la reflectancia en las rocas según su composición en minerales básicos parece claro que presentan siempre un máximo de diferenciación (Fig. 2) (3) entre los 550-650 nanómetros $(\mathrm{nm})$ dentro del espectro visible y alrededor de 900-1000 nm en el infrarrojo (Scanvic, 1989). Estas bandas de máxima diferenciación son aplicables también a los compuestos minerales que pudieran registrarse en los pigmentos.

Además podemos encontrarnos situaciones en las que aparezcan costras que cubran de forma masiva o milimétrica los dibujos, microorganismos que hayan colonizado tanto el soporte como las pinturas, o filtraciones de agua sobre la

(3) Agradecemos a Julia Sánchez, de la Unidad de Nuevas Tecnologías del Centro de Estudios Históricos del CSIC, la preparación y realización de las figuras 2 y 3 de este artículo. superficie que pueden incluso haber arrastrado los pigmentos. Circunstancias que distorsionan la diferenciación visual de los dos componentes básicos del estudio artístico y estilístico en proporciones que son desconocidas, pero cuyo comportamiento espectral debe ser discriminado para una adecuada identificación e interpretación de los elementos pictóricos. Por otra parte, desde el punto de vista de la conservación y el diagnóstico del estado de las pinturas también deben ser observados y tenidos en cuenta.

\section{B. Sensores y bandas espectrales}

Las imágenes pueden capturarse mediante diferentes dispositivos o sensores con resolución en diferentes longitudes de onda. En la elección juegan varios factores entre los que se pueden destacar dos íntimamente relacionados: el coste y el lugar de adquisición de la imagen. Una gran parte del trabajo con longitudes de onda distintas a la radiación visible ha sido realizado en museos y laboratorios que cuentan con un acondicionamiento adecuado y en los que el objeto es estudiado bajo condiciones controladas. En el caso del arte rupestre, las pinturas se localizan siempre en espacios naturales, más o menos accesibles, con áreas útiles para el trabajo generalmente reducidas. Todo el equipo debería ser trasladado e instalado en condiciones extremas, siendo necesario un esfuerzo adaptativo del equipamiento al espacio físico disponible. En consecuencia, inicialmente no tiene sentido trabajar con técnicas complejas si existe posibilidad de obtener información útil por otros medios.

Las cámaras fotográficas pueden trabajar de forma sencilla dentro de una variedad de longitudes de onda mediante la utilización de filtros y películas especiales. La fotografía multibanda puede obtenerse por tanto con equipos de fotogrametría convencional, cuya aplicación permite además un trabajo de reconstitución mucho más detallado que el realizado a partir de cal$\cos (4)$. La tarea de filtrado con el equipamiento adecuado logra eliminar la mayor parte de la

(4) Los tratamientos con CAD permiten generar una detallada información y reconstrucción de las pinturas (un ejemplo en Bell et alii, 1996). 
radiación no deseada, acotando la banda del espectro que interese. No se buscan anchuras de banda demasiado pequeñas, sino simplemente diferenciar las grandes regiones del espectro ultravioleta, visible (azul, verde y rojo) e infrarrojo próximo. En este último caso las películas especiales tienen sensibilidad hasta los $900 \mathrm{~nm}, \mathrm{y}$ existen productos sensibilizados hasta los $1350 \mathrm{~nm}$ que se emplean para trabajos científicos (5). En el ultravioleta se trabaja a partir de los $300 \mathrm{~nm}$, que es el límite de transmisión por objetivos de cristal.

Por tanto la utilización de filtros y películas especiales nos facilita al menos 5 imágenes diferenciadas con las que trabajar: ultravioleta, azul, verde, rojo e infrarrojo próximo, aunque en este último podrían obtenerse dos bandas diferentes (700-900 nm y 900-1100 nm). La selección de un tipo u otro de películas debe regirse por la sensibilidad espectral necesitada.

\section{Condiciones de trabajo}

Una norma esencial para la fiabilidad y contrastación del trabajo es operar con los mismos parámetros. Tanto la intensidad de iluminación como su ángulo de incidencia generan respuestas diferentes como ya se indicó anteriormente. La variación en la reflectancia a causa de esos factores se acentúa más o menos dependiendo de la longitud de onda. La transmitancia de los filtros o de las lentes cambia el registro según el ángulo de incidencia (por ejemplo, con un ángulo de $45^{\circ}$ (cambia de los $1300 \mathrm{~nm}$ a $1265 \mathrm{~nm}$ ) y el error aumenta cuanto más aumente el campo de visión (Casini et alii, 1992). También varía el grado de transmitancia en función de la longitud de onda, decreciendo significativamente a partir del infrarrojo próximo. En consecuencia, la captura de la imagen debe producirse bajo las mismas condiciones si deseamos establecer comparaciones entre figuras o entre conjuntos.

Trabajar en abrigos con pinturas colocadas en distintas posiciones y cuya orientación en relación a la iluminación natural es diferente,

(5) Agradecemos a la casa Kodak la información suministrada sobre material fotográfico a través de sus prospectos y en especial el de "Películas kodak infrarrojas". plantea la opción de utilizar iluminación artificial. Puesto que la intensidad y el ángulo de incidencia sobre los motivos pictóricos cambia en función de la época del año y la hora del día, la única forma de controlar estos parámetros es el empleo de fuentes de luz artificial. La conveniencia de utilizar luz blanca o halógena (amarilla) deberá ser estudiada en detalle para valorar su influencia en el resultado final. Además las propias condiciones de la toma fotográfica, como el tiempo de exposición y la apertura del diafragma, pueden mantenerse también fijas al establecerse condiciones constantes de iluminación. Favorecen la estrategia de la iluminación artificial tanto el empleo de fotografía ultravioleta, que exige el uso de lámparas de iluminación especiales, como el sistema de luz polarizada propuesto por Henderson (1995) para mejorar los contrastes entre pigmento y soporte, que más, adelante comentaremos.

Un problema fundamental en la documentación de las pinturas es el color. Son de todos conocidas las variaciones de color que generan la sensibilidad de las películas y su procesado. Finalmente las alteraciones químicas que el paso del tiempo producen en las fotografías también transforman los colores registrados.

Además en la percepción del color intervienen muchos factores distorsionantes que ocasionan una observación diferencial según cada individuo. La existencia de metámeros (6), así como las distorsiones según las condiciones de iluminación, forma y fondo (problema de la constancia del color) nos sitúan en un campo muy resbaladizo a la hora de la descripción de este elemento (Petrov, 1993).

Sin embargo, el color es un elemento descriptivo y comparativo esencial dentro del estudio artístico. En el trabajo con imágenes multiespectrales, donde se selecciona una banda determinada del espectro visible o se trabaja con radiación no visible, no es un problema primordial puesto que las variaciones de reflectancia de la materia que se están registrando

(6) Según la definición del término por la Real Academia de Ciencias Exactas, Físicas y Naturales: "cada uno de los estímulos luminosos con diferentes distribuciones espectrales de energía, capaces de producir en la visión fovela sensaciones idénticas de color". 
son las que interesa comparar, aunque una parte de ellas sea consecuencia del propio color. En este caso resulta más determinante el grado de resolución espacial y espectral que se pueda conseguir en la imagen digital.

La investigación en arte rupestre no puede prescindir del registro general de las pinturas por la importancia de la documentación de estas manifestaciones artísticas sometidas a un constante riesgo de desaparición y deterioro. En este terreno el color es útil para la reconstrucción fiel de cada una de las representaciones. A pesar de las dificultades para su definición y de las transformaciones que ocurren en el paso de una imagen analógica a otra digital, la expresión numérica de esta última podría ser eficaz en una estrategia comparativa, si no existiesen factores como las pátinas superficiales que hacen variar la reflectancia del color original del pigmento. Además pequeñas variaciones en el color pueden obedecer a una disolución diferente del pigmento (pequeñas oscilaciones en las proporciones de los elementos integrantes), a la diferente absorción o porosidad del soporte, $\mathrm{o}$ al diferente grado de arrastre o disolución sufrido por la pintura con el tiempo, factores fortuitos que no responden al conocimiento y ejecución técnica por parte del artista prehistórico. En este sentido pueden ser más indicativos los análisis sobre la composición de los pigmentos que el color final observado en la actualidad.

En nuestra investigación nos interesa discriminar en primer lugar la propia imagen pictórica y distinguir si existen diferencias dentro de ella; un segundo aspecto, más conflictivo a la vista de los comentarios anteriores, es la comparación de las características entre distintas imágenes, ya sea de una misma localidad o de otras.

Recientemente se ha señalado la conveniencia del uso de una escala calibrada de color que permita la reconstitución de los colores, con independencia de los factores que hayan afectado a la fotografía original. Según Bednarik y Seshadri (1995) es posible una corrección digital de las imágenes siempre y cuando estas dispongan de unas referencias de color conocidas y la escala cubra un porcentaje significativo $(>5 \%)$ de la imagen para permitir la calibración. La escala de color de la International Fe- deration of Rock Art Organizations (IFRAO) parece haberse convertido en una herramienta necesaria en el registro y documentación del arte rupestre. Su empleo en nuestra investigación permitiría una cierta homogeneización de los valores para la comparación de intensidades y tonos de color entre imágenes distintas, aunque una interpretación cultural a partir de las mismas resultaría muy arriesgada dada la dependencia de los factores físicos antes expuestos, cuya contrastación exigiría esfuerzos complementarios como estudios geomorfológicos de las estaciones rupestres.

Por último conviene comentar la obtención de imágenes mejoradas mediante una técnica para fotografiar el arte rupestre aplicando luz polarizada que resalta y diferencia los pigmentos de su base y minimiza el efecto de las capas superficiales y de los actos vandálicos sufridos por la pintura (Henderson, 1995). La luz reflejada tiene dos componentes: la reflectancia de la superficie que sigue un comportamiento regular en función de la textura, y una reflectancia de la subsuperficie procedente de la parte de la energía que atraviesa parcialmente la materia y que finalmente sale al exterior en diferentes direcciones debido a las interacciones que se producen en su camino. La posibilidad de separar ambas reflectancias se consigue mediante la polarización de la luz incidente, que será reflejada en la superficie en el mismo plano de polarización, mientras que la retrodispersa mantendrá distintas direcciones. Con el uso de un segundo filtro rotado 90 grados (polarización cruzada) la reflexión unidireccional de la superficie queda absorbida y únicamente es atravesada por todas aquellas procedentes de la subsuperficie. Aunque las superficies rocosas no son planas, ni lisas y no toda la luz reflejada mantiene la misma dirección, la reducción de la reflectancia de la superficie permitirá que la reflectancia difusa sea apreciada y registrada en mejores condiciones mediante el empleo de películas que acentúan el contraste y la saturación, dado el bajo nivel energético con el que se trabaja.

Todos estos elementos nos suministran imágenes que pueden ser sometidas a un proceso digital con la finalidad de mejorar nuestros conocimientos sobre el arte prehistórico y buscar nuevas vías de información. La combinación de

T. P., 53, n. ${ }^{\circ} 2,1996$ 


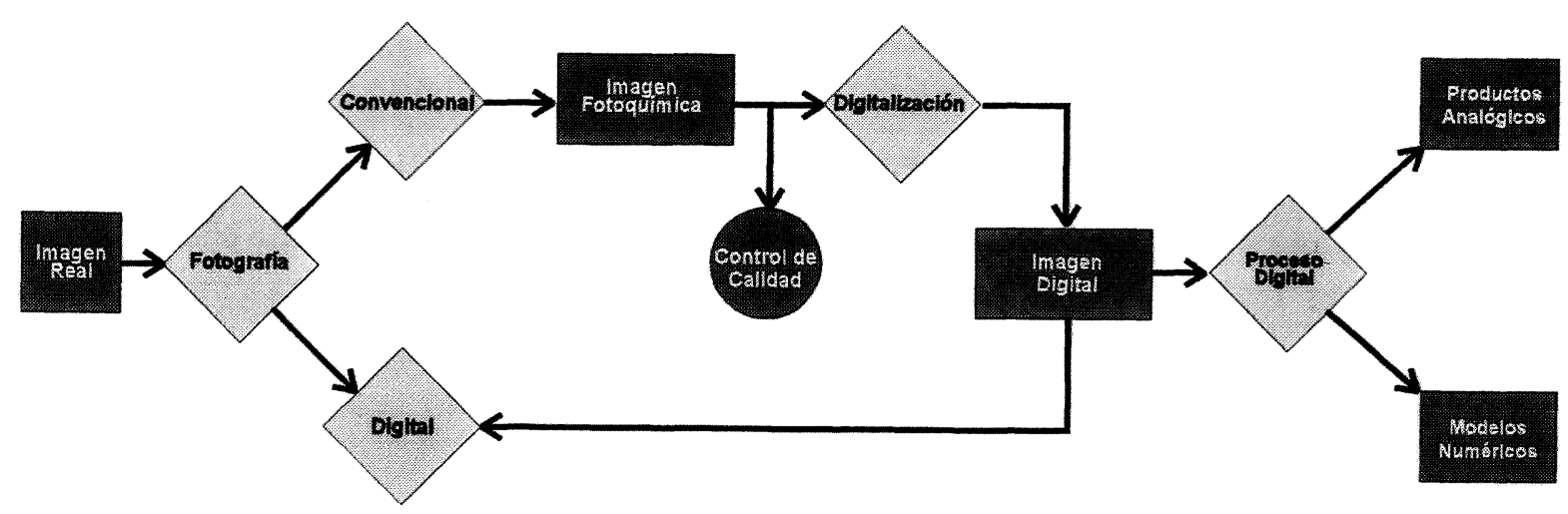

Fig. 3. Proceso de digitalización.

diferentes imágenes ayuda a descubrir nuevos elementos que la imagen visible no registra, al igual que ocurre con el uso de la radiación no visible.

La transformación de una imagen analógica a una digital (Fig. 3) no reviste en la actualidad grandes problemas dada la posibilidad de obtener directamente de la película un formato digital, sin necesidad de un revelado químico. Los escáneres de mesa también permiten conseguir resoluciones de trabajo adecuadas. En cambio las cámaras digitales que empiezan a comercializarse todavía mantienen precios elevados en relación a su resolución. El paso del tiempo quizás permita su utilización eliminando pasos en el proceso, pero nos queda la duda sobre su posible uso en la banda del infrarrojo.

\section{ANÁLISIS DE LAS IMÁGENES}

Una vez obtenida una determinada serie de imágenes en formato digital y dentro de las herramientas de trabajo disponibles en la teledetección espacial es posible estudiar la discriminación de los elementos presentes con métodos estadísticos o con un análisis previo de separabilidad a través de diagramas de signaturas, que son similares a las gráficas de reflectancia espectral (Pinilla, 1995: 231-235). Entramos, por tanto, en las fases de procesado y análisis, que trataremos brevemente a través de un ejemplo seleccionado para mostrar las potencialidades del sistema, manejando el análisis de
Componentes Principales, aunque no responda a todas las exigencias previas de trabajo y su interpretación final pueda ser debatida por la falta de control en las variables de partida.

\section{A. Análisis de Componentes Principales}

La técnica de componentes principales trata de representar un conjunto de variables observadas en un grupo de elementos, mediante un número inferior de nuevas variables formadas a partir de combinaciones lineales de las variables originales.

Desde el punto de vista geométrico, la técnica de componentes principales no es más que un cambio de coordenadas que define unos nuevos ejes ortogonales como direcciones principales del conjunto de puntos. La ventaja de esta nueva forma de representación es la ausencia de correlación entre las variables.

Para comprender mejor por qué, y en aras de una cierta rigurosidad, es necesario un pequeño apunte sobre su razonamiento matemático puesto que es, esencialmente, una transformación geométrica (Fig. 4).

Llamamos matriz de covarianzas a la siguiente matriz simétrica:

$$
\Sigma=\left(\begin{array}{cccc}
\sigma_{11} & \sigma_{12} & \ldots & \sigma_{1 n} \\
\sigma_{21} & \sigma_{21} & \ldots & \sigma_{2 n} \\
\ldots & \ldots & \ldots & \ldots \\
\sigma_{n 1} & \sigma_{n 2} & \ldots & \sigma_{n n}
\end{array}\right)
$$




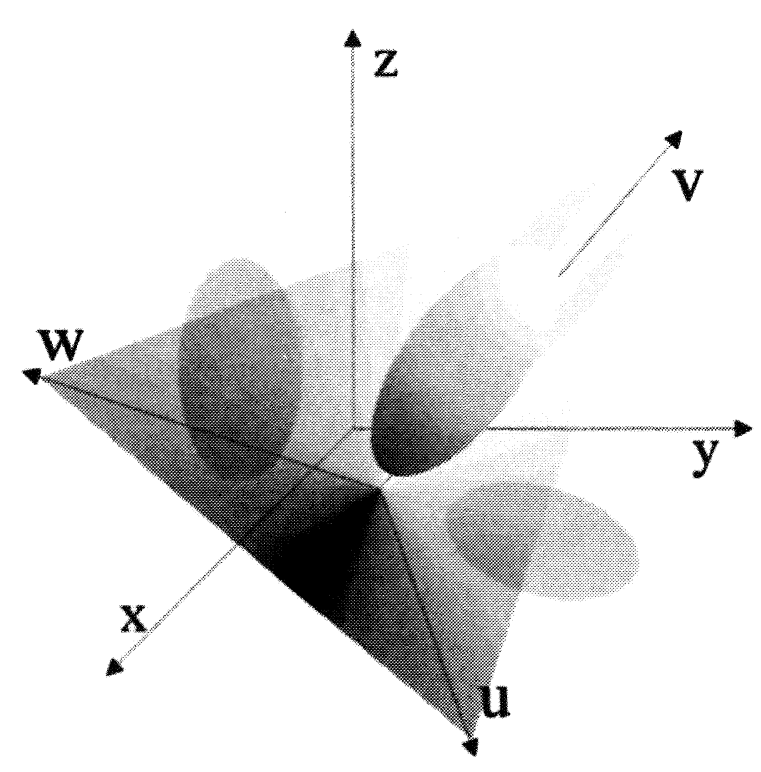

Fig. 4. Transformación a componentes principales en un espacio tridimensional.

Como $\sum$ es simétrica, es diagonalizable (Loughlin, 1991: 1964). Sea la ecuación característica $|\Sigma-\lambda \mathbf{I}|=0$ cuyas raíces son los valores propios $\lambda_{1}, \lambda_{2}, \ldots, \lambda_{\mathrm{i}}, \ldots, \lambda_{\mathrm{n}}$ y ordenados de forma que $\lambda_{1} \geq \lambda_{2} \geq \ldots \geq \lambda_{\mathrm{I}} \geq \ldots \geq \lambda_{\mathrm{n}}$ representando, la primera variable, la dirección más representativa del conjunto. Sean los vectores propios $\vec{v}_{i}$ para cada valor propio $\lambda_{\mathrm{i}}$ y la matriz:

$$
\mathrm{V}=\left(\begin{array}{c}
v_{1} \\
v_{2} \\
\vdots \\
v_{\mathrm{i}} \\
\vdots \\
v_{n}
\end{array}\right)=\left(\begin{array}{ccc}
v_{11} & \ldots & v_{1 n} \\
v_{21} & \ldots & v_{2 n} \\
\ldots & \ldots & \ldots \\
v_{i 1} & \ldots & v_{i n} \\
\ldots & \ldots & \ldots \\
v_{n 1} & \ldots & v_{n n}
\end{array}\right)
$$

llamaremos transformación a componentes principales a la transformación lineal $\mathrm{Z}=\mathrm{V} \cdot \mathrm{X}$ siendo $V$ la matriz ortogonal obtenida con los vectores propios de $\Sigma$; esto es:

$$
\left(\begin{array}{c}
z_{1} \\
\vdots \\
z_{n}
\end{array}\right)=\left(\begin{array}{ccc}
v_{11} & \ldots & v_{1 n} \\
\ldots & \ldots & \ldots \\
\ldots & \ldots & \ldots \\
v_{n 1} & \ldots & v_{n n}
\end{array}\right)\left(\begin{array}{c}
x_{1} \\
\vdots \\
x_{n}
\end{array}\right)
$$

T. P., 53, n. ${ }^{\circ} 2,1996$
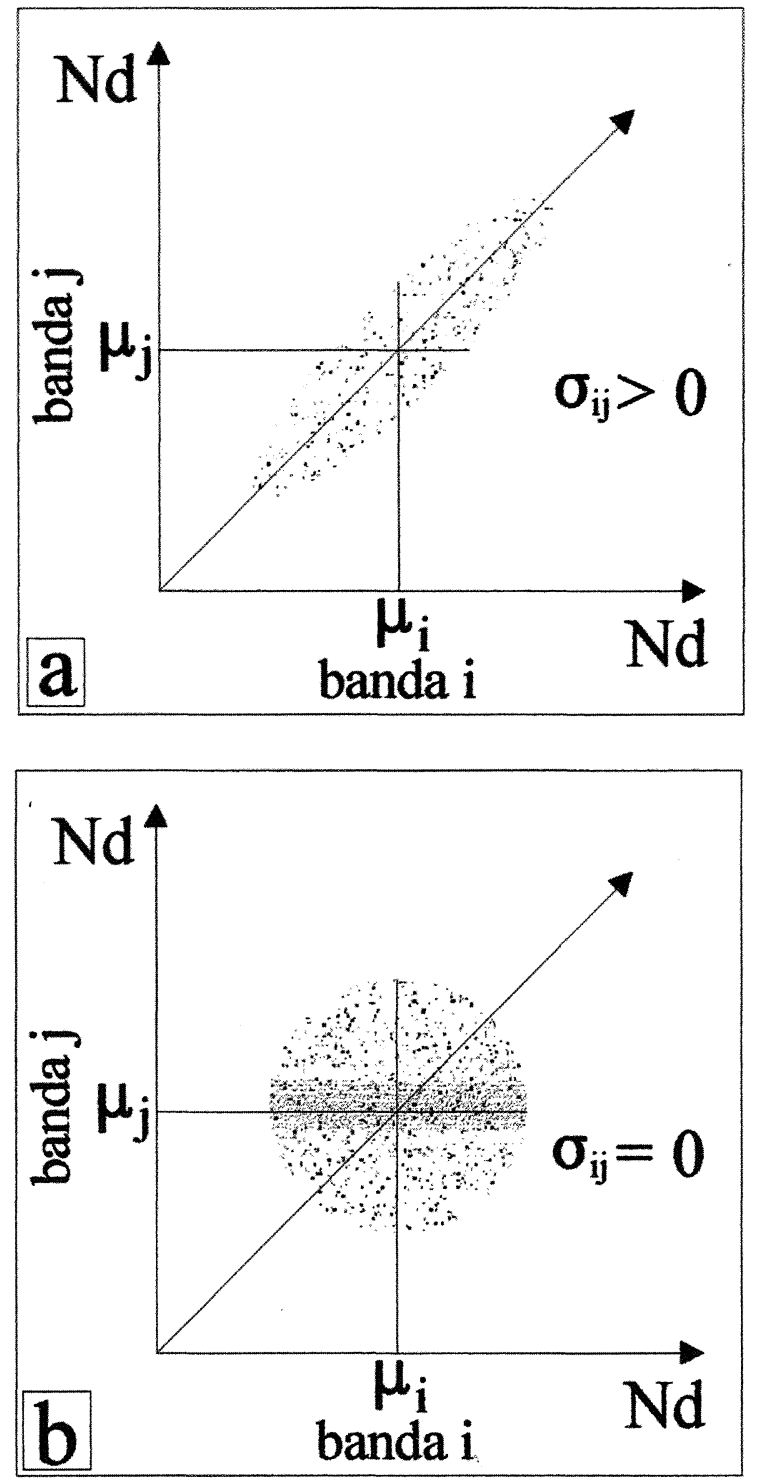

Fig. 5. A) Convarianza positiva. Conducción positiva entre las bandas i y j; B) Covarianza nula. Bandas i y j incorreladas.

Como la varianza se conserva (7) $\sigma_{1}^{2}+\ldots+$ $\sigma_{\mathrm{n}}^{2}=\lambda_{1}+\ldots+\lambda_{\mathrm{n}}$ y están ordenadas, la de mayor varianza es $\lambda_{1}$. De esta manera, las nue-

(7) Teorema de la conservación de la traza (suma de los elementos de la diagonal principal) en una transformación lineal $\operatorname{tr}(\Sigma)=\operatorname{tr}(\mathrm{D})$, siendo $\mathrm{D}$ la matriz diagonal (todos los elementos que no pertenecen a la diagonal principal son nulos). 
vas variables $\mathrm{Z}$ se dice que están incorreladas, es decir, la matriz correspondiente es diagonal y las covarianzas son nulas.

Veamos la representación geométrica de este razonamiento: supongamos 3 variables correlacionadas $x_{1}, x_{2}, x_{3}$ (Fig. 5a), un ángulo recto tiene coseno de 0,0 , lo que implica que la correlación entre las variables también será 0 , lo que es lo mismo, tendremos variables ortogonales o incorreladas (Fig. 5b).

Obsérvese que aún no hemos hablado de Análisis de Componentes Principales (ACP) sino de Transformación a Componentes principales (TCP). Esta última es una técnica muy utilizada en proceso de imagen en general y en teledetección espacial particularmente, como herramienta para eliminar la redundancia en la información.

Una cantidad indeterminada de información es aprehendida por el sensor en diferentes bandas, es decir, algunas de las características que se observan en el rojo, también están presentes en el Azul y el Verde o el infrarrojo. La TCP, como hemos visto, genera nuevas bandas que no sólo son distintas entre sí, sino que también lo son de las que se han obtenido.

La principal utilidad de la TCP es la reducción de la variabilidad de la información suministrada por el sensor (8). Otra aplicación más importante, desde el punto de vista del arte rupestre, es la capacidad de obtener información no visible de los paneles con pinturas.

La TCP supone, pues, la utilización de las nuevas variables, en nuestro caso bandas, que ya no son ni rojo, ni verde, ni azul, sino que presentan características de los elementos representados: como veremos más adelante, la humedad superficial, la diferente composición de los pigmentos o la estructura de la concreción calcárea. El problema de esta transformación es que no siempre estas nuevas imágenes, son fáciles de interpretar. Es en este momento cuando se inicia la fase de análisis.

Esto quiere decir que la varianza se redistribuye sin pérdidas sobre los componentes principales.

(8) En el caso del sensor Landsat-5 TM, suministra siete bandas sobre la superficie cuya variabilidad puede ser reducida a tres (conteniendo alrededor del $98 \%$ de la varianza), facilitando la interpretación y el tiempo de cálculo del ordenador.
Como hemos visto, la aplicación de técnicas de proceso digital de imagen al estudio del arte rupestre es bastante escasa, esto implica necesariamente una cierta reserva en cuanto a la interpretación de las imágenes analizadas, de la que nosotros somos conscientes. Ahora bien, las imágenes obtenidas mediante TCP son reveladoras de ciertos aspectos no observables a simple vista.

\section{B. Un caso práctico: el arquero del abrigo de la Saltadora}

En el Laboratorio de Proceso Digital de Imagen y Teledetección se estudió una serie de imágenes pertenecientes a la figura $25 \mathrm{del}$ abrigo de la Saltadora III (Cuevas de Vinromá, Castellón) (Lám. II) que se corresponden con los intervalos 450-520 $\mathrm{nm}$ (Azul), 520-600 nm (Verde) y 630-690 nm (Rojo) del espectro visible (Fig. 1). Como la imagen original es analógi$\mathrm{ca}$, al digitalizarla pierde resolución espacial (el objeto más pequeño que puede observarse en una imagen). En nuestro caso esta pérdida de información no representó un grave inconveniente puesto que partimos del fotograma pancromático digital del CPRL. Se tomó la decisión de trabajar con imágenes a media resolución (9) que compensaba el tiempo de proceso con una cantidad de información aceptable.

Una vez obtenidas las tres imágenes, y ya en la fase de procesado, se calculan los estadísticos que definen las poblaciones de puntos (pixeles). Esta tarea implica la localización y corrección de errores ocurridos durante la digitalización: la falta de alguna línea, la corrección de la gama debida al ajuste del escáner, o la presencia de algún tipo de ruido. Para ello se aplican técnicas típicas de retoque fotográfico como el filtrado. La labor es delicada debido a que cualquier tipo de retoque variará los valores originales de los pixeles y por tanto el resultado de los análisis de forma que, cuanto menos se retoque la imagen, menor será el error de asigna-

(9) Esta resolución es la correspondiente a la media resolución del formato Kodak Photo CD, esto es: 512 x 768, en la cual conseguimos un tamaño de pixel de menos de 3 ó 4 milímetros. 


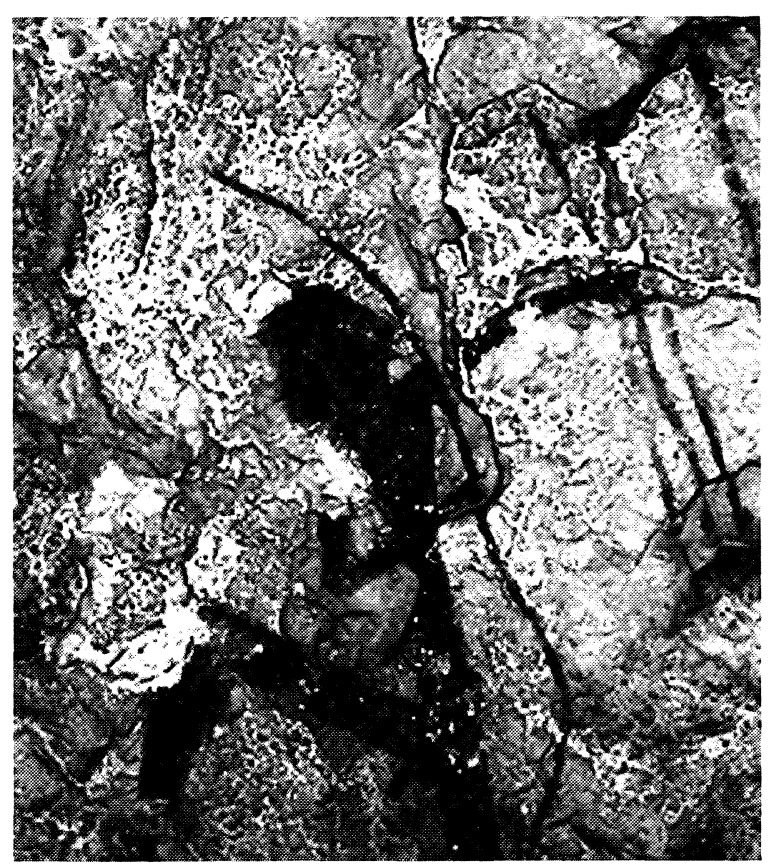

Lám. II. Figura 25 del abrigo III de La Saltadora (Cuevas de Vinromá, Castellón). Tamaño $13 \mathrm{~cm}$. Fotografía tomada el X-73 (CPRL del Departamento de Prehistoria del C.E.H.)

ción en la fase posterior. Así pues, en la fase de procesado, el retoque debe entenderse como un intento de acercamiento de la representación de la realidad (la imagen) al original.

Obtenidas las imágenes con la calidad necesaria se ha procedido a su tratamiento como bandas independientes mediante un programa de proceso digital de imagen de satélite (10), dentro ya de la fase de análisis.

Se realiza la transformación a componentes principales (CPI, CPII y CPIII) (Lám. III) y, una vez calculados los estadísticos de las nuevas bandas, se estudian sus histogramas. Se procede entonces a un análisis exploratorio de las mismas. En CPI está concentrada la mayor parte de la varianza de la escena de forma que podemos entender ésta como una generalización de las propiedades del conjunto: El histograma de ésta presenta dos picos, esto es, dos clases principales si dejamos al margen lo que representa el soporte. El segundo y tercer com-

(10) ER-MAPPER versión 5.2. ponente discriminan información que podemos considerar como no visible, y contienen un porcentaje mucho menor de la varianza. Es aquí donde hemos observado los rasgos más destacables, puesto que se hacen ahora evidentes elementos que no eran apreciables en la imagen original: el CPII parece una imagen negativa del componente I, y si en este último podíamos observar de forma más clara que en la imagen pancromática tanto las escoriaciones del soporte como las concreciones calcáreas, es en el segundo componente donde podemos separar claramente unas de otras.

El CPIII tiene un interés añadido para el seguimiento de los problemas de conservación. Claramente se destacan, en el lado derecho de la imagen (Lám. III) las flechas sobre las que apoya su mano el arquero. Hasta esta imagen no habíamos podido diferenciar el pigmento de la figura del de las flechas. Éstas se parecen en CPI y CPII a algunas áreas del interior del cuerpo de la figura. No podemos decir si estas diferencias se deben a su factura o a la conservación diferencial del pigmento debida a la acción de los agentes atmosféricos, pero sí podemos decir que existe una diferencia sustantiva entre estas partes de la figura.

Esta fase finaliza con la realización de un mapa de clases del panel, para lo cual la mejor fuente son los componentes principales, puesto que, como hemos dicho, no se ha perdido prácticamente nada de la variación original de la escena.

La presencia de pixeles con los mismos valores en algunas partes del arco, de las piernas y el torso de la figura hacen pensar que podía deberse al silueteado de la misma en alguna fase de su ejecución, e incluso que se utilizaron pigmentos distintos para las diferentes partes de la composición. De cualquier modo, como se puede observar en las imágenes, éstas tienen valor por sí mismas al revelar aspectos que se escapan al ojo humano o, al menos, el tiempo y el trabajo invertidos en su discriminación es mucho menor. Una interpretación ajustada de la variabilidad de la escena pasaría por la siguiente fase de análisis.

Después de clasificar una imagen se necesita asignar el origen de la variación a cada una de las clases. La analítica físico-química de algunos puntos significativos del panel, la medi- 


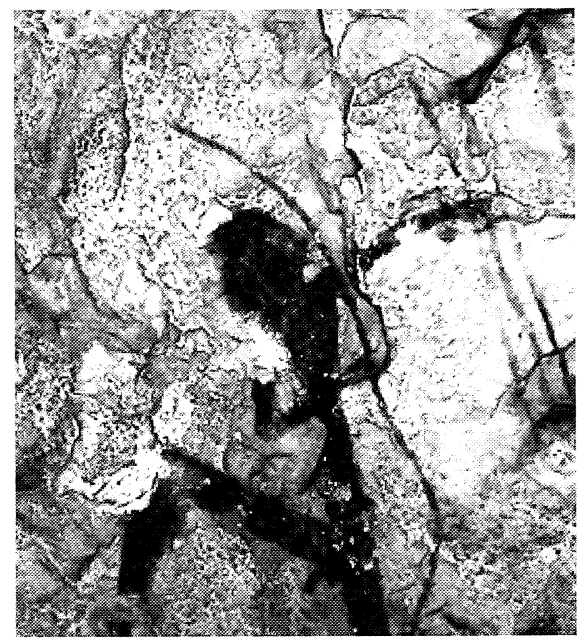

\section{Rojo}

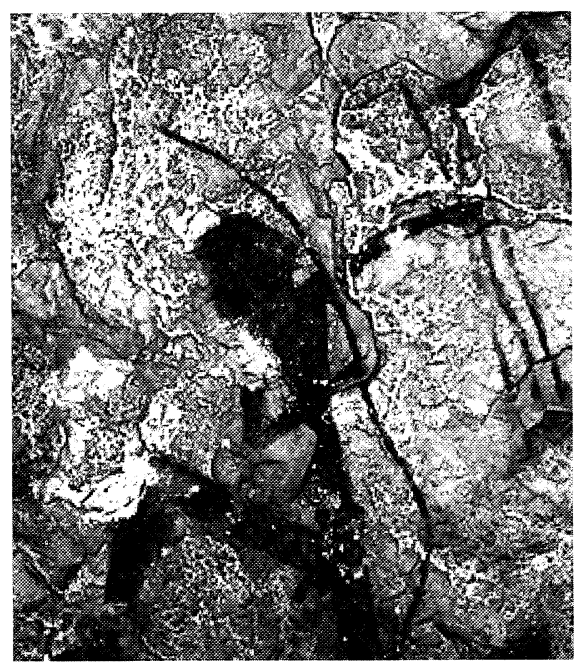

\section{Verde}

CPI
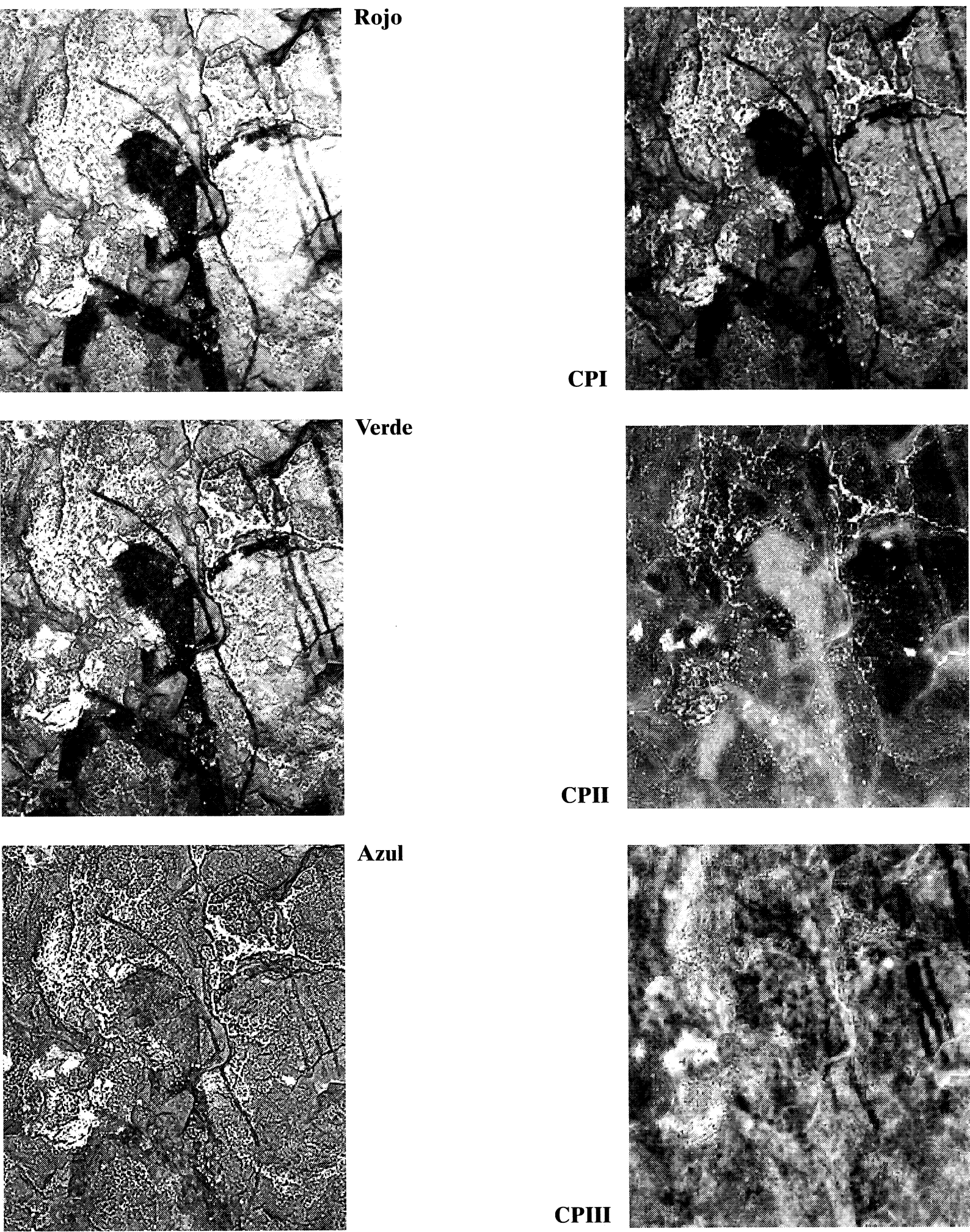

Azul

CPII

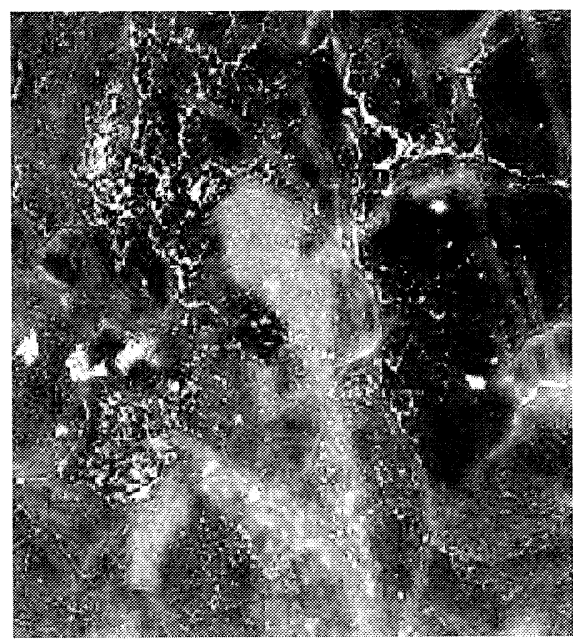

CPIII

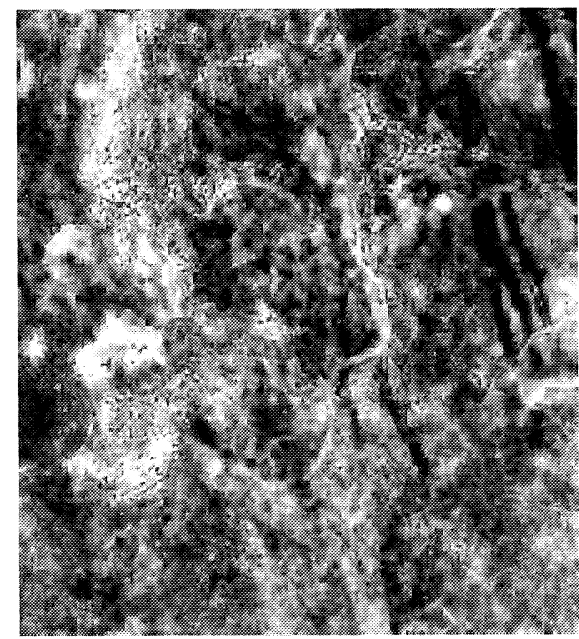

Lám. III. Bandas analizadas de figura 25 del abril III de La Saltadora y Componentes principales obtenidos de ellas. 
da de la humedad superficial, o el grado de insolación de otros tantos permitirán generalizar los resultados a todo el panel y confeccionar un mapa exhaustivo de estas y otras variables.

Como veíamos más arriba, la toma de imágenes con cámaras y técnicas de fotogrametría a corta distancia, permiten generar modelos digitales del panel de gran utilidad tanto en la evaluación de su estado de conservación, como en la modelización de algunos de los factores que inciden en el deterioro de las estaciones de arte rupestre.

El último paso sería la toma de decisiones. Podemos separar en dos vertientes, no necesariamente antagónicas, los usos que se pueden dar a los sistemas de análisis que hemos presentado: por una parte la conservación de los conjuntos, por otra la investigación arqueológica en sentido estricto.

El montaje de una estación de seguimiento (o en su defecto el alquiler de servicios a un equipo especializado) permite, con un coste reducido, estudiar de forma eficaz y con gran precisión el curso que sigue un conjunto mediante la realización de series temporales de imágenes. Se cuenta así con un diagnóstico solvente y actualizado para, en su caso, aplicar las medidas de protección necesarias (11).

Además el tratamiento de las imágenes permite abordar algunas cuestiones como la ejecución técnica de las figuras, la realización de calcos, la visualización de aspectos ocultos con posibles implicaciones en el análisis de superposiciones, etc., que cubren los temas de investigación del presente proyecto. Su objetivo final es generar una rutina de trabajo válida para la aplicación de estas técnicas de tratamiento digital de la imagen al estudio y conservación del arte rupestre postpaleolítico. Confiamos que estas páginas hayan puesto de manifiesto la potencialidad y virtualidad de esta novedosa línea de investigación.

(11) En este aspecto es donde los componentes principales han demostrado ser una de las mejores herramientas que tenemos a nuestra disposición (Balairón, 1995: 255).

\section{BIBLIOGRAFÍA}

AcostA, P. (1986): “Arte rupestre postpaleolítico hispano". En A. Montenegro (coord.): Historia de España. Prehistoria. Editorial Gredos S.A. Madrid: 265-299.

ANDREW, S.R. Y EASTOP, D. (1994): "Using ulta-violet and infra-red techniques in the examination and documentation of historic textiles". The Curator, 18: 50-56.

Aujoulat, N. (1987): Le relevé des oeuvres pariétales paléolithiques. Documents d'Archéologie Française, 9. Editions de la Maison des Sciences de l'Homme. Paris.

BALAIRÓN Ruíz, L. (1995): "Análisis de la variabilidad espacial y temporal en los procesos meteorológicos" En J.J. Ibáñez y C. Machado (eds.): Análisis de la variabilidad espacio-temporal y procesos caóticos en ciencias medioambientales. Geoforma Ediciones. Logroño: 243-258.

Baronti, S.; CAsini, A.; LotTI, F.; Porcinal, S.; y STEFANI, L. (1996): "The application of principal component analysis to an investigation of hyper-spectral data imaged in the visible and near-infrared regions. Preliminary results on the 'Predella della Trinita' by Luca Signore1li". Art'96. $5^{\text {th }}$ International Conference of nondestructive testing, microanalytical methods and environmental evaluation for study and conservation of works of art. September 24-28, 1996. Budapest: 101-115.

BEDNAIK, R.G. (1993): "The direct dating of rock art". Rock Art Research, 10(1): 48-51.

BEDNARIK, R.G. y SESHADRI, K. (1995): "Digital colour re-constitution in rock art photography". Rock Art Research, 12(1): 42-51.

Bell, J.; Jerôme, J-P.; Sawyer, P.; Magar, V. y Price, N.S. (1996): "Stereophotogrammetric recording of rock art at the Cueva de El Ratón, Baja California, Mexico". ICOM Committee for Conservation. $11^{\text {th }}$ Triennial Meeting Preprints. Edinburgh, 1996. James \& James Ltd. London: 454-57.

Beltran, A. (1982): De cazadores a pastores. El Arte rupestre del Levante español. Ediciones Encuentro. Madrid.

Benito, G.; Machado, M.J. y SANChO, C. (1991-92): “Alteración de las areniscas y la conservación de las pinturas rupestres del Rodeno de Albarracín (Teruel)". $\mathrm{Ka}$ lathos, 11-12: 7-24.

Casini, A.; Lotti, F.; Baronti, S.; Castagna, P. y StefaNI, L. (1992): "An image spectroscopy system for the analysis and documentation of paintings". Science and Technology for Cultural Heritage, 1: 33-43.

Cosens, M. (1989): “Comments". Rock Art Research, 6(1): 15.

Delaney, J.K.; Metzger, C.; Walmsley, E. y Fletcher, C. (1993): "Examination of the visibility of Underdrawing lines as a function of wavelength". Scientific Examination of Work of Art. ICOM Commitee for Conservation $10^{\text {th }}$ Triennial Meeting Preprints, Washington, 1993: 15-19.

Dickman, J.L. (1989): "Comments". Rock Art Research, $6(1): 15-16$.

FleTCHER, S.J. (1992): “A longer view: the preservation of panoramic Cirkut negatives at the Indiana Historical Society". En The imperfect image: photographs, 
their past, present and future. Conference proceedings: papers presented at the Centre for Photographic Conservation's first international conference at the Low Wood Conference Centre, Windermere, $6^{\text {th }}-10^{\text {th }}$ April, 1992. Centre for Photographic Conservation. London: 304-309.

HENDERSON, J.W. (1995): “An improved procedure for the photographic enhancement of rock paintings". Rock Art Research, 12 (2): 75-85.

Koch, M.S. Y GRUBER, A. (1994): "Die Erhaltung und Bewahrung von fotographischen Materialien". En M. Koller y R. Prandtstetten (eds.): "Zum Thema Papier und Graphik”. Restauratorenblätter, 14: 107-116.

LAHANIER, C. (1991): "Scientific methods applied to the study of art objects". Mikrochimica acta, 2: 245-254.

LAUTENBACH, A. (1992): "Duplication on photographic imagery". En The imperfect image: photographs, their past, present and future. Conference proceedings: papers presented at the Centre for Photographic Conservation's first international conference at the Low Wood Conference Centre, Windermere, $6^{\text {th }}-10^{\text {th }}$ April, 1992. Centre for Photographic Conservation. London: 134-136.

Loughlin, W.P. (1991): "Principal Component Analysis for Alteration Mapping". Photogrammetric Engineering and Remote Sensing. 57(9): 1163-1169.

Minzoni-Deroche, A.; Menu, M. y Walter, Ph. (1995): "The working of pigment during Aurignacian period: evidence from Uçagizli cave (Turkey)". Antiquity, 69: 153-158

Menu, M. y Walter, Ph. (1992): "Prehistoric cave painting: PIXE analysis for the identification of paint 'pots". Nuclear Instruments and Methods in Physics Research.B, 64: 547-552.
Moneva, MaD. (1993): "Primeros sistemas de reproducción de arte rupestre en España”. Espacio Tiempo y Forma, Serie I, 6: 413-441.

PEdersen, A. (1953-54): "El infrarrojo y su aplicación en la investigación de pinturas rupestres". Runa, 6: 216-219.

Petrov, A.P. (1993): "Surface color and color constancy". COLOR research and application, 18(4): 236-240.

Pinilla, C. (1995): Elementos de Teledetección. Ra-Ma. Madrid.

RIP, M.R. (1989): "Colour space transformations for the enhancement of rock art images by computer". Rock Art Research, 6(1): 12-14.

Russ, J.L. (1994): Radiocarbon dating of prehistoric rock paintings. UIM Dissertation Services, 1416. Michigan.

SCANVIC, J-Y. (1989): “Teledetección aplicada”. Paraninfo S.A. Madrid.

SLACK, C. (1994): "The enhancement of radiographs through digital image processing". Science \& Technology, 3: 8-9.

Vicent García, J.M. (1993): “El Departamento de Prehistoria”. En M ${ }^{a}$ I. Martínez Navarrete (coord.): Teoría y práctica de la Prehistoria: perspectivas desde los extremos de Europa. Servicio de Publicaciones de la Universidad de Cantabria. C.S.I.C. Santander, Madrid: 19-35.

- (1994): "La digitalización del archivo de arte rupestre post-paleolítico del Departamento de Prehistoria del Centro de Estudios Históricos (C.S.I.C.), Madrid". Boletín del Instituto Andaluz de Patrimonio, 7: 41-43.

VRHEL, M.J.; GERSHON, R. y IwAN, L.S. (1994): "Measurement and analysis of object reflectance spectra". COLOR research and application, 19(1): 4-9. 